\title{
Herpes zoster ophthalmicus presenting as giant cell arteritis
}

\section{Introduction}

An 80-year-old man was referred urgently by his general practitioner (GP) for assessment of possible giant cell arteritis (GCA), also known as temporal arteritis. Seven days earlier, patient developed acute shooting pain to the right temporal region. There was scalp parathesia but no jaw claudication and no vision disturbance. Investigations performed by GP included erythrocyte sedimentation rate (ESR) $8 \mathrm{~mm} / \mathrm{hr}, \mathrm{C}$-reactive protein $<1 \mathrm{mg} / \mathrm{L}$ and temporal artery ultrasound which reported, "the right temporal artery did demonstrate a halo sign at multiple locations in keeping with GCA (Figure 1)."

Right temporal artery biopsy was done (22 $\mathrm{mm}$ long) and showed, "age-related arteriosclerosis. There is no evidence of arteritis."

The author assessed the patient seven days after he first developed the symptoms. Patient was already on prednisolone $50 \mathrm{mg}$ daily. Patient was uncertain whether the headache improved from the prednisolone or paracetamol. More history showed patient has background of diabetes, prostate cancer ten years ago treated with bicalutamide and goserelin. Examination showed right temporal area was tender but the temporal artery was pulsating normally with no enlargement, no discolouration and no nodularity. Vision was normal. There was no sign of large vessels involvement.

Careful inspection of the skin showed mild raised papular rash on the right forehead and above the right eyebrow (Figure 2, with patient consent). The rash was swabbed. Both swabs from the forehead and near the eyebrow tested positive for varicella zoster virus on polymerase chain reaction. The zoster rash became more obvious a week later (Figure 3).
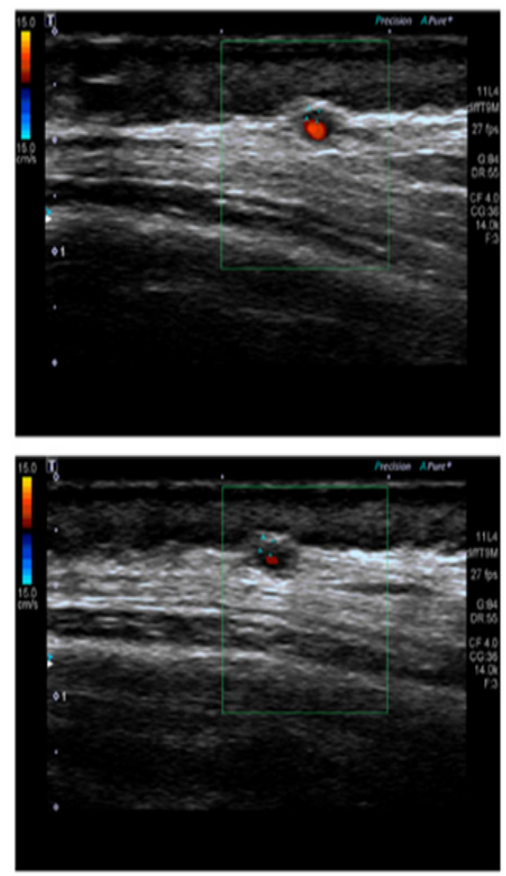

Figure I Halo sign on temporal artery ultrasound.
Volume 7 Issue 5 - 2017

\section{Jeffrey Tsai}

Department of Rheumatology, Gold Coast University Hospital, Australia

Correspondence: Jeffrey Tsai, Department of Rheumatology, Gold Coast University Hospital, Australia,

Email jeffreytsai88@gmail.com

Received: October 23, 2017 | Published: November 08, 2017
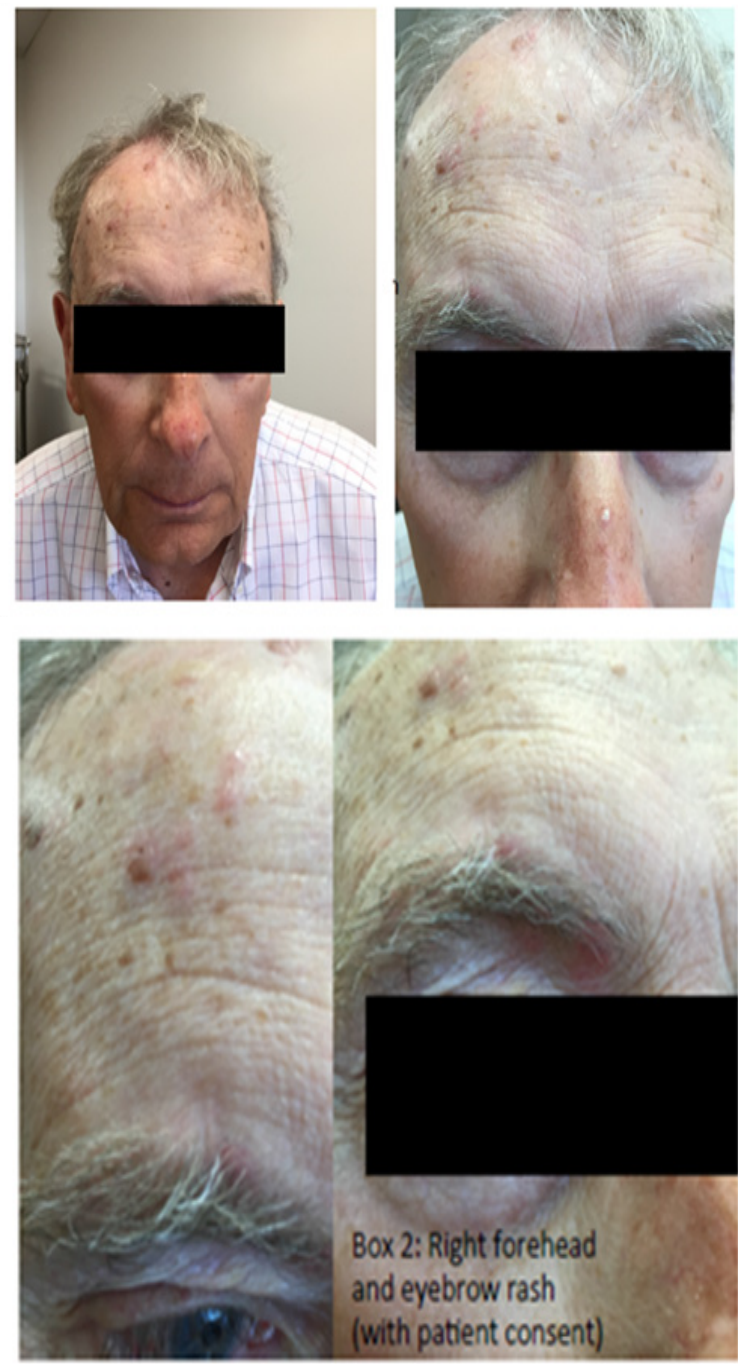

Figure 2 Right forehead and eyebrow rash (with patient consent). 


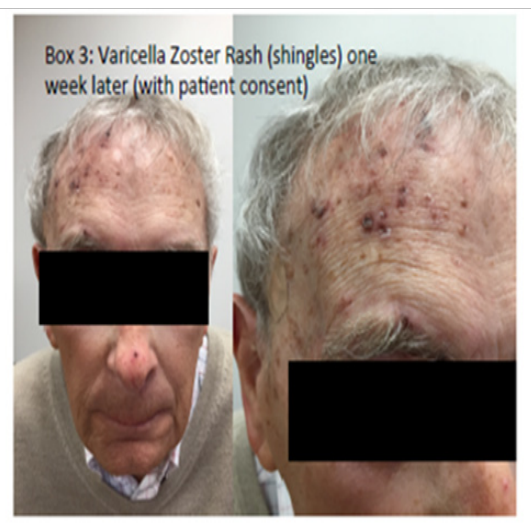

Figure 3 The zoster rash one week later.

Patient was referred to ophthalmology for the diagnosis of herpes zoster ophthalmicus. For completeness, viral stain was added to the temporal artery specimen but the stain was negative. After the diagnosis, patient wanted to follow up with his GP and ophthalmologist. His headache had improved significantly without any vision changes.

\section{Discussion}

Herpes zoster ophthalmicus is a serious sight threatening condition associated with reactivation of varicella zoster virus in the trigeminal nerve. It is associated with headache. Treatment is antiviral therapy. ${ }^{1}$

This was a case of suspected GCA but turned out to be shingles. Diagnosis of GCA can be challenging as the common features, such as temporal artery abnormality and elevated ESR, are not always present. ${ }^{2}$ However, due to the potential devastating consequence of irreversible blindness from missed GCA, it is reasonable to treat an older patient with new and unexplained temporal headache as GCA until proven otherwise. Glucocorticoid is the recommended treatment for GCA. Glucocorticoid is also recommended for reducing the pain associated with shingles. ${ }^{3}$ However, the distinction between GCA and shingles remains important as it determines the duration of glucocorticoid that is particularly important in this patient with diabetes.

Recently, there have been several studies suggesting possible association of varicella zoster virus and GCA. ${ }^{4}$ However, as this case demonstrates, the direct causal role of varicella zoster virus in GCA is still lacking and needs further research.
Similarly, studies on the usefulness of temporal artery ultrasound are mixed. A meta-analysis suggested halo sign, stenosis and occlusion have sensitivity and specificity as high as 88 and 78 percent. ${ }^{5}$ Other study reported sensitivity of biopsy-proven GCA was only 40 percent. ${ }^{6}$ As this case shows, temporal artery ultrasound does not replace temporal artery biopsy as the critical test for patients with suspected GCA.

\section{Lessons from practice}

i. Consider herpes zoster ophthalmicus as a differential diagnosis in patients with suspected GCA.

ii. Evaluation of GCA requires comprehensive history, careful examination, and judicious use of investigations.

iii. Beware of false positive temporal artery ultrasound.

iv. Treat suspected cases as GCA until proven otherwise. Only change management when there is a secured alternative explanation.

\section{Acknowledgements}

None.

\section{Conflict of interest}

The author declares no conflict of interest.

\section{References}

1. Liesegang TJ. Diagnosis and therapy of herpes zoster ophthalmicus. Ophthalmology. 1991;98(8):1216-1229.

2. Salvarani C, Cantini F, Boiardi L, et al. Polymyalgia rheumatica and giant-cell arteritis. $N$ Engl J Med. 2002;347(4):261-271.

3. Therapuetic Guidelines: Neurology, version 4, Neuropathic pain; 2011.

4. Gilden D, White T, Khmeleva N, et al. Prevalence and distribution of VZV in temporal arteries of patients with giant cell arteritis. Neurology. 2015;84(19):1948-1955.

5. Karassa FB, Matsagas MI, Schmidt WA, et al. Meta-analysis: test performance of ultrasonography for giant-cell arteritis. Ann Intern Med. 2005;142(2):359-369.

6. Salvarani C, Silingardi M, Ghirarduzzi A, et al. Is duplex ultrasonography useful for the diagnosis of giant-cell arteritis? Ann Intern Med. 2002;137(4):232-238 